\title{
Editorial \\ Preoperative evaluation of morbid obese patients
}

Volume 2 Issue 2 - 2015

\section{Editorial}

Morbid obesity is an exponentially growing health issue. World Health Organization predicts that the population of morbid obese people will be 700 millions in $2015 .^{1}$ This means that us, the physicians will be facing with an increasing number of obese or even super obese (body mass index $>55 \mathrm{kh} . \mathrm{m}^{2}$ ) patients. ${ }^{2}$ Previously, we used to encounter with morbid obesity patients for "bariatric surgery" but now-a-days we come across with morbid obese patients during all types of surgical interventions.

Morbid obesity is a metabolic disorder in which the patient's bodymass index (BMI) (weight/height ${ }^{2}$ ) is over 40 and is accompanied with co-morbidities such as obesity induced hypertension and diabetes. $^{2}$ Difficulty in securing the airway and impairment in the respiratory functions in morbid obese patients are challenges for the anesthesiologists. We always carry the concern if a morbid obese patient undergoing surgery for various reasons will be able to extubated successfully at the end of the surgery without the need of postoperative intensive care unit. As a result, morbid obese patients have to wait for vacancy in already limited intensive care unit beds to get operated. This waiting period both causes a psychological stress on the patient and increases the cost. So what can we, the anesthesiologists do about this? Before all else, we must identify if the patients will be in need of postoperative intensive care unit support for respiratory problems by a thorough and detailed pre anesthetic visit. There is no common ground about the parameters that will help us to achieve this prediction. According to the studies done, the importance given to the respiratory function tests evaluation changes from clinic to clinic. In our clinic, we do not solely evaluate respiratory function tests because the value of the respiratory function test can change according to the success of coordination between the patients and the administrator. Instead we also use arterial blood gas samples and the results of the exercise test we administer to the patient preoperatively to come up with a prediction.

Respiratory functions of the morbid obese patients have not only obstructive pattern but also restrictive impairment as the diaphragm forces the lungs up. Morbid obese patients also have chronic intraabdominal hypertension. ${ }^{1,2}$ Thus it is harder for them to synchronize with the test. The importance of the evaluation of the arterial blood gas samples is a fact. In addition to that, starting to use the older "bed side tests" ( breath holding test, valsalva test, forced respiratory test, cough test, walk test) during the pre anesthetic visit once again will simplify the respiratory and cardiac evaluation of morbid obese patients and decrease the rate of advanced examination need. In our clinic, we have modified the "6minute walk test" into "60meters 60 seconds walk test" for a study. ${ }^{3-7}$ In our study we have asked the patients to walk a 60 meter straight corridor under 60 seconds. Our aim was to investigate if this test was predictive for extubation. We have measured the pre and post walk test peripheral oxygen saturation, systemic arterial blood pressure, heart rate values and forced expiratory tidal volumes (FEV) via "Wright Spirometer". We have observed the peripheral oxygen saturation of the patients during the walk test by using a portable oximeter. In the statistical analysis, we have determined that morbid obese patients whose FEV values increased compared to the

\section{Guniz M Koksal, Emre Erbabacan}

Department of Anesthesiology and Reanimation, Istanbul University Cerrahpasa Medical School,Turkey

Correspondence: Guniz M Koksal, Department of Anesthesiology and Reanimation Kocamustafapasa, Istanbul University Cerrahpasa Medical Faculty, Fatih, Istanbul,Turkey, Tel 0905424138505, Email gunizkoksal@hotmail.com

Received: March 01, 2015 | Published: March 25, 2015

pre-test values and peripheral oxygen saturation values stayed same or increased were extubated instantly following the end of the surgery.

\section{Conclusion}

We concluded that the exercise executed in this test might have opened some of the obesity related atelectasis by facilitating deep inspiration. "60meters 60 seconds Walk test" is effective and practical in evaluating the respiratory functions and effort capacity of the patients with no cost. We believe that starting to re-use the bed side tests such as "valsalva test" that enlightens us about the cardiac functions (left ventricular insufficiency, mitral stenosis, aorta stenosis, constrictive pericarditis etc.); "forced respiratory test" that gives us information about the maximum breathing capacity and vital capacity; "breath holding test" where we use in diagnosing severe respiratory diseases; "cough test" which is predictive for postoperative pulmonary complications, can facilitate the work of anesthesiologists.

\section{Acknowledgments}

None.

\section{Funding details}

None.

\section{Conflicts of interest}

Authors declare that there is no conflict of interest.

\section{References}

1. Domi R, Laho H. Anesthetic challanges in the obese patient. $J$ Anesth. 2012;26(5):758-765

2. Huschak G, Busch T, Kaisers UX. Obesity in anesthesia and intensive care. Best Pract Res Clin Endocrinol Metab. 2013;27(2):247-260.

3. Kohn RM. Breath-holding test for cardiac states. Circulation. 1959;20:721-722.

4. Snider TH, Stevens JP, Wilner FM, et al. Simple bedside test of respiratory function. JAMA. 1959;170(14):1631-1632. 
5. Greene BA, Berkowitz S. Preanesthetic induced cough as a method of diagnosis of preoperative bronchitis. Ann Intern Med. 1952;37(4):723-732.

6. Ard RW, Twining RH. Evaluation of valsalva test in bedside diagnosis of dyspnea. Am J Med Sci. 1957;234(4):403-412.
7. Ciftci F, Sen E, Akkoca Yıldız O, et al. A comparison of cardiopulmonary exercise test and 6 minute walking test in determination of exercise capacity in chronic obstructive pulmonary disease. Tuberk Toraks. 2014;62(4):259-266. 